\title{
Not all that glitters is gold - Electron microscopy study on uptake of gold nanoparticles in Daphnia magna and related artefacts
}

Jensen, Louise Helene Søgaard; Skjolding, Lars Michael; Thit, Amalie; Sørensen, Sara Nørgaard; Købler, Carsten; Mølhave, Kristian; Baun, Anders

\section{Published in:}

Environmental Toxicology and Chemistry

Link to article, DOI:

10.1002/etc.3697

Publication date:

2017

Document Version

Peer reviewed version

Link back to DTU Orbit

Citation $(A P A)$ :

Jensen, L. H. S., Skjolding, L. M., Thit, A., Sørensen, S. N., Købler, C., Mølhave, K., \& Baun, A. (2017). Not all that glitters is gold - Electron microscopy study on uptake of gold nanoparticles in Daphnia magna and related artefacts. Environmental Toxicology and Chemistry, 36(6), 1503-1509. https://doi.org/10.1002/etc.3697

\section{General rights}

Copyright and moral rights for the publications made accessible in the public portal are retained by the authors and/or other copyright owners and it is a condition of accessing publications that users recognise and abide by the legal requirements associated with these rights.

- Users may download and print one copy of any publication from the public portal for the purpose of private study or research.

- You may not further distribute the material or use it for any profit-making activity or commercial gain

- You may freely distribute the URL identifying the publication in the public portal 


\section{Environmental \\ Toxicology and Chemistry}

Environmental Chemistry

NOT ALL THAT GLITTERS IS GOLD - ELECTRON MICROSCOPY STUDY ON UPTAKE

OF GOLD NANOPARTICLES IN DAPHNIA MAGNA AND RELATED ARTEFACTS

louise Helene Søgaard Jensen, Lars Michael Skjolding, Amalie Thit, Sara NørgaARd Sørensen, Carsten Købler, Kristian Mølhave, and Anders Baun

Environ Toxicol Chem., Accepted Article • DOI: 10.1002/etc.3697

\section{Accepted Article}

"Accepted Articles" are peer-reviewed, accepted manuscripts that have not been edited, formatted, or in any way altered by the authors since acceptance. They are citable by the Digital Object Identifier (DOI). After the manuscript is edited and formatted, it will be removed from the "Accepted Articles" Web site and published as an Early View article. Note that editing may introduce changes to the manuscript text and/or graphics which could affect content, and all legal disclaimers and ethical guidelines that apply to the journal pertain. SETAC cannot be held responsible for errors or consequences arising from the use of information contained in these manuscripts.

This article is protected by copyright. All rights reserved 
Environmental Chemistry Environmental Toxicology and Chemistry DOI 10.1002/etc.3697

\author{
NOT ALL THAT GLITTERS IS GOLD - ELECTRON MICROSCOPY STUDY ON UPTAKE OF \\ GOLD NANOPARTICLES IN DAPHNIA MAGNA AND RELATED ARTEFACTS
}

Running title: Analysis of gold nanoparticles in Daphnia magna gut

Louise Helene SøgaArd Jensen, $* \dagger$ Lars Michael SkJolding, + Amalie Thit, $\S$ Sara NørgaARd Sørensen, $\$$ Carsten Købler, || Kristian Mølhave, $\|$ and Anders Baun

$\nmid$ Center for Electron Nanoscopy, Technical University of Denmark, Kgs. Lyngby, Denmark †Department of Environmental Engineering, Technical University of Denmark, Kgs. Lyngby, Denmark $\S$ Department of Science and Environment, Roskilde University, Roskilde, Denmark ||Department of Micro- and Nanotechnology, Technical University of Denmark, Kgs. Lyngby, Denmark

* Address correspondence to louise.jensen@epfl.ch

This article contains online-only Supplemental Data

This article is protected by copyright. All rights reserved Submitted 15 July 2016 ; Returned for Revision 21 August 2016 ; Accepted 23 November 2016

This article is protected by copyright. All rights reserved 
Abstract: Increasing use of engineered nanoparticles has led to extensive research into their potential hazards to the environment and human health. Cellular uptake from the gut is sparsely investigated and microscopy techniques applied for uptake studies can result in misinterpretations. Various microscopy techniques are used to investigate internalization of $10 \mathrm{~nm}$ gold nanoparticles in Daphnia magna gut lumen and gut epithelial cells upon 24h exposure and outline potential artefacts, i.e. high contract precipitates from sample preparation related to these techniques. Light sheet microscopy confirmed accumulation of gold nanoparticles in the gut lumen. Scanning transmission electron microscopy and elemental analysis revealed gold nanoparticles attached to the microvilli of gut cells. Interestingly, the peritrophic membrane appeared to act as a semipermeable barrier between the lumen and the gut epithelium, permitting only single particles through. Structures resembling nanoparticles were also observed inside gut cells. As elemental analysis could not verify these to be gold they were likely artifacts from the preparation, such as osmium and iron. Importantly, gold nanoparticles were in fact found inside holocrine cells with disrupted membranes. Thus, false positive observations of nanoparticle internalization may result from either preparation artefacts or by mistaking disrupted cells for intact. These findings emphasize the importance of cell integrity and combining elemental analysis with the localization of internalized nanoparticles using transmission electron microscopy. This article is protected by copyright. All rights reserved

Keywords : Nanotoxicology, Nanoparticles, Freshwater toxicology, Aquatic invertebrates

This article is protected by copyright. All rights reserved 


\section{INTRODUCTION}

Use of engineered nanoparticles (NPs) has increased rapidly over the past decade and consequently it is important to evaluate their environmental fate and potential effects. Most studies have focused on assessing toxicity of NPs, while less is known about bioaccumulation of these particles [1]. The uptake of NPs in aquatic organisms and in particular the cellular internalization following uptake are matters of crucial importance for understanding the potential effects of NPs.

Electron Microscopy (EM) is a well-established technique for imaging of biological samples, including cellular ultra-structures. High resolution images of biological structures can be achieved by EM, with chemically or cryo fixed biological specimens [2]. In addition EM has become a vastly used technique in the field of nanotechnology, for characterizing the primary particle size and morphology of NPs [3-5]. More recently, EM techniques are increasingly being applied for detection of NPs in biological samples, to examine uptake and internalization of NPs in cells of whole aquatic organisms [6-10]. While Garcia-Alonso et al. [7] observed cellular uptake of NPs from the gut in the estuarine polychaete Nereis diversicolor and Santo et al. in D. magna [10] most studies using EM imaging are inconclusive and/or report no or limited detection of NP internalization $[6,8,9]$ albeit disturbed gut cells [8]. The use of EM techniques such as transmission electron microscopy (TEM) also involves the risk of misinterpretation of results obtained from microscopy of NP internalization. Edgington et al. [11] found structures similar to single-walled carbon nanotubes in D. magna. However, additional analyses using high resolution TEM, Energy Dispersive X-ray Spectroscopy (EDX) and selected area diffraction revealed that the observed structures were in fact either staining artefacts or amorphous carbon. Brandenberger et al. [12] studied the cellular uptake of Quantum Dots (QD) in murine macrophage-like cells and found electron dense structures inside the cells. With Electron Energy Loss Spectroscopy (EELS) analysis they showed that only one area out of the six that were originally

This article is protected by copyright. All rights reserved 
believed to contain quantum dots, did in fact contain them. The particle-like structures found in the other areas were probably either precipitates from the post staining or osmophilic structures within the sample [12].

This type of study underline that we are still in the infancy of imaging and characterizing the uptake of NPs in organisms. Furthermore, it shows that the understanding of the mechanisms and artefacts associated with assessment of in vivo distribution of NPs can be improved.

Daphnia magna is a widely used model organism in ecotoxicological studies due to their ecological relevance and limited maintenance requirements in the laboratory. Furthermore, they are ideal for bioaccumulation studies with NPs as they are transparent which enables visualization of accumulated material, including agglomerations of NPs, in the gut. In addition, their filter feeding behavior results in the filtration of large volumes of water, including suspended NPs. D. magna can filter particles down to around the size of $200 \mathrm{~nm}$ out of their feeding current. However, smaller particles are also available for uptake through either direct interception $[13,14]$ or by drinking the surrounding media $[15,16]$. Previous studies have shown uptake and accumulation of Au NPs in the gut of D. magna either by measurements of accumulated Au [17] or based on observations of a darklycolored gut [18-20]. In addition, Au NPs have been shown to be taken into the gut of D. magna by trophic transfer with E. gracilis and C. reinhardtii [21]. Hence, uptake into the gut is a likely route of exposure for NPs in D. magna.

Au NPs have several properties that make them ideal for bioaccumulation studies, including relatively low toxicity and high stability in suspension, e.g. limited dissolution and aggregation. In addition, their high mass density increases contrast and detection with EM.

The aim of the present study was to examine uptake of Au NPs into D. magna gut lumen and potential internalization into gut cells using multiple microscopy techniques: Light Sheet Microscopy (LSM), Focused Ion Beam Scanning EM (FIB-SEM), TEM, High-Angle Annular Dark-Field Scanning 
Transmission EM (HAADF-STEM) and elemental analysis with EDX. In addition, the aim was to examine the potential artefacts related to microscopy which may lead to misinterpretation regarding NP internalization into cells.

\section{MATERIALS AND METHODS}

\section{Nanoparticles}

Citrate stabilized Au NPs in suspension were synthesized at the University of Alberta, Canada by Dr. Jonathan GC Veinot and Guibin Ma as described by Skjolding et al. [17]. The manufacturer of the Au NPs reported a primary size of $10 \mathrm{~nm}$. The particles were non-aggregated as imaged by cryoTEM of a prepared stock solution containing $40 \mathrm{mg} \mathrm{Au} / \mathrm{L}$ in MilliQ water (Figure 1) and the size was validated by TEM and DLS before ingestion (Supplemental Data, Figure S1 and Table S2 [17]).

Fluorescein isothiocyanate (FITC) labeled Au NPs were synthesized according to Jølck et al. [22] and used to allow imaging of NPs in whole organisms using LSM.

Exposure of Daphnia magna to $\mathrm{Au} N P s$

The test suspensions for D. magna exposures were prepared immediately prior to exposure by adding the required amount of stock suspension into Elendt M7 medium [23] in a volumetric flask to a concentration of $0.4 \mathrm{mg} \mathrm{Au} / \mathrm{L}$. This concentration was used for all exposures and chosen from previous studies showing marked uptake at this concentration [17].

No stirring or ultra-sonication was applied. The D. magna was cultured at DTU Environment in Elendt M7 medium in a temperature-controlled room at $20( \pm 1){ }^{\circ} \mathrm{C}$ with a $12 \mathrm{~h}: 12 \mathrm{~h}$ light: dark cycle.

D. magna neonates (<24h old) were exposed to $0.4 \mathrm{mg} \mathrm{Au} / \mathrm{L}$ for $24 \mathrm{~h}$ in $100 \mathrm{ml}$ beakers containing $25 \mathrm{~mL}$ test solution. In addition, controls without added Au NPs were included in each test series. Beakers with five $D$. magna neonates in each were incubated in the dark at $20( \pm 1){ }^{\circ} \mathrm{C}$ without feeding. After $24 \mathrm{~h}$ exposure the animals were removed from the test beakers and gently rinsed in Elendt M7 medium to remove potential Au NPs adhered to the exoskeleton. 
For LSM additional D. magna $(\mathrm{n}=3)$ was exposure to fluorescently labelled Au NPs in $1.5 \mathrm{~L}$ aquariums filled with $1 \mathrm{~L}$ exposure solution. Exposure suspensions of $1 \mathrm{mg} \mathrm{Au} / \mathrm{L}$ were prepared immediately prior to exposure, without the use of sonication or prolonged stirring. Exposed daphnia were sampled at different time points and analyzed in the LSM. Similarly, unexposed controls were also analyzed with LSM. Time points used for uptake phase were 1, 2, 4 and $24 \mathrm{~h}$. No feeding was carried out during the uptake phase.

\section{Specimen preparation for EM}

D. magna (both exposed animals and controls) were washed in sodium cacodylate buffer $(0.15 \mathrm{M})$, fixed in $2 \%$ glutaraldehyde in $0.05 \mathrm{M}$ cacodylate buffer for $1 \mathrm{~h}$ at room temperature. Specimens were washed twice in sodium cacodylate buffer $(0.15 \mathrm{M})$, post-fixed in $1 \% \mathrm{OsO}_{4}$ with 0.02 $\mathrm{M} \mathrm{KFeCN}$ in $0.12 \mathrm{M}$ cacodylate buffer, rinsed three times in MilliQ water, submerged for 1 hour in $1 \%$ w:vol tannic acid and washed three more times in MilliQ water and en bloc stained with 1\% (w/vol) uranyl acetate for $2 \mathrm{~h}$. Specimens were dehydrated in a series of 2x10 min steps using ethanol of $70 \%$, $96 \%, 100 \%$. After 2x 10 min dehydration in propylene oxide specimens were infiltrated by gradually increasing Epon (embed 812, standard recipe) to propylene oxide ratio in a series of steps: 1:3 for 30 min, 1:1 overnight, 3:1 for $1 \mathrm{~h}$ and pure Epon for $2 \mathrm{~h}$. Finally specimens were embedded and cured at 60 ${ }^{\circ} \mathrm{C}$ for $72 \mathrm{~h}$.

Semi-thin sections $(1 \mu \mathrm{m})$ were obtained with a Leica Ultracut UCT ultramicrotome using glass knifes made on a knife maker (LKB instrument group 7800). Ultra-thin sections were obtained using a RMC MT-7 ultramicrotome and a diamond knife (Ultra 45, Diatome). Semi-thin sections were placed on a glass slide and stained with toluidine blue for light microscopy (Olympus BX51 microscope) to localize the gut for EM.

To rule out the possibility of Au NP transfer into D. magna gut resulting from the preparation steps, two methodological controls were included. Au NPs were added at two different steps of the 
sample preparation (referred to as controls C1 and C2). For C1 Au NPs were added with the uranyl acetate during en bloc staining. For C2, Au NPs in acetone was used instead of propylene oxide during infiltration. Au NP suspension in acetone was obtained by gentle heating and evaporation of water from stock suspension and the subsequent suspension of Au NPs in acetone.

Specimen preparation for LSM

Before LSM imaging the daphnia were briefly transferred to clean media to rinse off exterior bound NPs. The daphnia were anesthetized to avoid movements during microscopy. For anesthesia $17 \%$ ethanol and $0.55 \mathrm{mg} / \mathrm{L}$ phenoxyethanol solutions in VH US EPA media $\left(0.24 \mathrm{~g} / \mathrm{L} \mathrm{CaSO}_{4} * 2 \mathrm{H}_{2} \mathrm{O}\right.$, $0.24 \mathrm{~g} / \mathrm{L} \mathrm{MgSO}_{4} * 7 \mathrm{H}_{2} \mathrm{O}, 0.016 \mathrm{~g} / \mathrm{L} \mathrm{KCl}$ and $0.384 \mathrm{~g} / \mathrm{L} \mathrm{NaHCO}_{3}$ in MilliQ water) was used. After anesthesia the test organisms were embedded in freshly prepared 1\% low temperature melting agarose in an Eppendorf tube. The agarose solution was kept in a heating block at $38^{\circ} \mathrm{C}$ to keep it liquefied. To avoid thermal damage of the daphnia the Eppendorf tube containing agarose was briefly taken off the heating block before embedding. Appropriate glass capillary and plunger was used to suck the test organism from the agarose solution. Care was taken to keep the daphnia vertically aligned with the capillary to receive the best penetration of light from all angles when imaged. When solidified in the agarose (approximately $1 \mathrm{~min}$ ) the test organism was imaged in the LSM.

\section{EM and elemental analysis}

FIB-SEM (Quanta FEG 3D, FEI) was conducted on entire epoxy embedded specimens mounted on a holder and gold coated (High Resolution Sputter Coater, Cressington). A cross section of the gut was made by milling a trench into the sample. Imaging was done with a low-kV high contrast backscatter detector at $5 \mathrm{kV}$. Ultra-thin sections of 80-100 nm were placed on copper grids $(\mathrm{Cu}, 3 \mathrm{~mm}$, 250 mesh square, SPI-grids) for TEM (CM 100 Phillips, operating voltage $80 \mathrm{kV}$ ). Ultra-thin sections $(70 \mathrm{~nm})$ were placed on carbon coated grids $(\mathrm{Cu}, 3 \mathrm{~mm}, 200$, Agar scientific) and carbon coated (208C, Cressington) prior to HAADF STEM \& EDX (Tecnai G2 T20, FEI, operating voltage $200 \mathrm{kV}$ ). 
Elemental analysis of single NPs was conducted in STEM mode with EDX $\left(80 \mathrm{~mm}^{2} \mathrm{X}-\mathrm{Max}\right.$ SDD detector, Oxford Instruments). Cryo-TEM (Tecnai G2 T20, FEI, operating voltage 200 kV) was performed using a single tilt liquid nitrogen cryo-transfer holder (626, Gatan) with Au NP stock suspension which had been placed on a lacey carbon grid (Agar scientific) and plunge-frozen in liquid ethane using a Vitrobot (FEI).

\section{$L S M$}

The LSM was performed using a Lightsheet Z.1 (Carl Zeiss Microscopy) equipped with a 5x objective, using the standard exposure chamber filled with VH US EPA media for imaging of the daphnia. Imaging of the samples was carried out using two lasers, $566 \mathrm{~nm}$ (laser 1) and $488 \mathrm{~nm}$ (laser 2). Broad pass filters with a range of 505-545 $\mathrm{nm}$ and 575-615 $\mathrm{nm}$ were used for laser 1 and 2, respectively. A laser intensity of 3 and $10 \%$ was used for laser 1 and 2, respectively, during the imaging of the uptake of Au NPs in daphnia. The exposure time used for all the samples was set to $154.8 \mathrm{~ms}$. The imaging was performed with two-sided illumination to obtain maximum illumination of the sample and avoid shaded areas. All imaging was performed as a series of slides referred to as the “z-stack" using an optimal thickness of the slides determined by the ZEN software (Carl Zeiss Microscopy). Furthermore, a 3D-multiview of the sample was made by rotation of the samples at 6 different angles $\left(0^{\circ}, 60^{\circ}, 120^{\circ}, 180^{\circ}, 240^{\circ}, 300^{\circ}\right.$ and $\left.360^{\circ}\right)$. When complete, the image were fused and averaged with a pixel average of 3 in the $\mathrm{x}$ and $\mathrm{y}$ direction. A maximum intensity projection was created to evaluate the overall uptake of the Au NPs.

\section{RESULTS AND DISCUSSION}

\section{Distribution of Au NPs at organism level}

The in vivo distribution of fluorescently labelled Au NPs in D. magna after 0, 2, 4 and 24h exposure to fluorescein (FITC)-labelled Au NPs imaged by LSM shows a continuous increase in fluorescent signal from the gut with time in Figure 2.

This article is protected by copyright. All rights reserved 
After 24 hours the gut was filled with fluorescent Au NPs. No fluorescent signal could be observed outside the gut of the daphnia. It is observed that initially the Au NPs accumulates in the hindgut as expected for inorganic particles with no nutritional value [24]. The fluorescent tag is covalently bound to the nanoparticles thus digestion of the fluorescent label is unlikely. The $\mathrm{pH}$ in Daphnia magna varies from $\mathrm{pH}$ 6-7.2 with increasing $\mathrm{pH}$ from the midgut to the anus. Consequently, no harsh environment in relation to $\mathrm{pH}$ is encountered after ingestion of the Au NPs and at physiological $\mathrm{pH}$ there was no change in the emission peak of the fluorescent tag. Preliminary embedding of FITC-labelled Au NPs dispersed in agarose showed no signal, thus only larger clusters of fluorescent Au NPs would be observed (data not shown). Similar observations were made by Rothen-Rutishauser et al. [25] using laser scanning microscopy, in a study demonstrating that clusters of approximately $150 \mathrm{Au}$ NPs would yield a fluorescent event. Thus, localization of dispersed NPs is not possible with this method which underline the need for reliable EM procedures.

\section{Distribution of Au NPs in the gut with EM}

FIB-SEM images (back scattered electrons, BSE) of D. magna exposed to Au NPs showed the gut lumen and surrounding cellular structures (Figure 3). A strong BSE signal was registered from the gut lumen, indicating regions with high concentration of Au NPs and thus uptake into the gut (Figure 3A, arrow), which was also expected based on images from LSM. The peritrophic membrane (PTM) appeared to retain the Au NPs in the gut lumen, except for single bright spots, which could possibly be Au NPs, observed near the microvilli (Figure 3B). However, elemental analysis of small particles outside the aggregates was not possible because of the relatively small volume of a $10 \mathrm{~nm}$ gold particle compared to the interaction volume of a $5 \mathrm{kV}$ electron beam.

TEM images of gut cross section from D. magna exposed to Au NPs exhibited regions of electron dense material within the gut lumen indicating the presence of Au NPs (Figure 4), asterisk). Mostly single electron dense particles and a few small aggregates were observed near the microvilli of 
the epithelial gut cells (Figure 4, arrows), again indicating that the PTM acts as a low permeability membrane between the microvilli and the lumen. The PTM is generally assumed to consist of chitin and proteins, and creates a barrier with a pore size of approximately $10 \mathrm{~nm}$ [26]. It has previously been suggested to act as a barrier for NP access to D. magna gut cells [9]. Therefore, we find it likely that agglomerates of Au NPs are retained in the gut lumen by the PTM. However, as single Au NPs are of similar size as the PTM pores, single Au NPs may possibly cross the PTM and reach the microvilli of the gut cells. Au-NP like objects were indeed observed across the PTM associated with the microvilli of gut cells (Figure 5A). Furthermore, structures with high contrast and similar size as the Au NPs were also observed inside cells, suggesting cellular internalization of Au NPs (Figure 5B).

\section{Elemental analysis with HAADF-STEM and EDX}

To further investigate the occurrence of Au NPs in D. magna subsequent imaging and analysis were conducted using HAADF-STEM imaging and EDX to facilitate elemental analysis of single particles. The results revealed that the identification of NPs solely on observations (i.e. contrast, size and morphology) can be deceiving, especially for NPs inside the cellular matrix where both nano-sized cellular structures and precipitates can exhibit similar contrast and size ranges. The large Au NP aggregate-like structures retained by the PTM inside the gut lumen (Figure 4, asterisk) were confirmed to be Au by STEM EDX (Supplemental Data, Figure S3). In all samples of exposed D. magna, objects were observed both across the PTM and inside cells exhibiting size, shape and contrast similar to that of the Au NPs used in the study. Elemental analysis of single particles with STEM EDX was conducted for a large number of high contrast Au NP-like objects found associated with or inside cells. Examples are shown in Figure 6.

Particles attached to the surface (Figure 6A) and at the base of microvilli (Figure 6B) were clearly distinguishable, due to the high contrast and characteristic shape of the NPs. Elemental analysis confirmed that these particles were Au. Inside the gut cells of exposed D. magna, high contrast material 
was found mainly in mitochondria and lipid droplets. High contrast precipitates in mitochondria gave mainly osmium signals (Figure 6C), as did particles found in lipid bodies (Figure 6D) and an aggregate of high contrast particles below the basal lamina contained iron and aluminum (Figure 6E). Of 64 particles found inside gut epithelial cells in 5 replicate animals and separately analyzed, none were confirmed to be Au. Furthermore, the 64 particles which were analyzed were only a fraction of the total number of particles observed inside cells. However, the majority of these were clearly not Au NPs when imaged in HAADF STEM and hence were not subjected to analysis. An additional source of artifacts in performing TEM of NP uptake can be imaging and analysis of particles inside dying cells. In this case, analysis is not a guarantee against false positives. The gut of D. magna undergo rapid turnover and holocrine cells in which the cell content is packed into vesicles and released by disruption of the cell wall into the gut lumen together with digestive enzymes [27] were seen throughout the sections. Within these cells, we could observe NPs which were confirmed to be Au (Figure 6F). This is not surprising, considering that the cell membrane was no longer intact, but in some images, the cells were early in the process and it was difficult to distinguish them from intact cells. This might lead to incorrect conclusions regarding uptake of NPs even when performing elemental analysis. No confirmed Au NPs (by STEM EDX) were identified inside the C1 and C2 control organisms or blank controls (Supplemental Data, Figure S4).

Internalization of NPs can take multiple routes depending on nanoparticle size, shape, surface charge and surface coating. Small particles are able to passively pass through cell membranes as shown in red blood cells which do not have an endocytic machinery [28, 29]. Both in vivo and in vitro studies have proposed NP uptake through endocytosis [7, 30, 31]. Larger NPs (approximately $100 \mathrm{~nm}$ ) have been suggested to be taken up actively by endocytosis whereas smaller NPs (approximately $10 \mathrm{~nm}$ ) have been suggested to accumulate on the cell membrane until the aggregates reach a certain size, resulting in uptake [32]. In case of long-time exposure to low numbers of NPs where threshold 
densities of NPs on the cell membrane is insufficient, passive uptake might be a significant route of internalization [32]. Assuming that either aggregation of small particles on the surfaces of cells or long exposure time is necessary to facilitate uptake, it is possible that the small NPs in our study are simply not interacting with enough receptors on the cell surface to mediate an immediate response; especially since only single particles were seen to cross the PTM, across which they did not form large aggregates. Larger aggregates were isolated from the gut epithelial cells by the PTM.

Lovern et al. [6] found few $\sim 20 \mathrm{~nm}$ Au NPs close to microvilli in D. magna in an intake experiment the animals were exposed up to 24 hours. This is in contrast to the results from Khan et al. that D. magna did neither internalize $\sim 20 \mathrm{~nm}$ Au NPs in its gut cells nor were the NPs associated with the microvilli of the gut epithelium [9]. The animals were exposed for 5 hours and allowed to depurate before analysis. In contrast to these findings, we found a considerable amount of Au NPs very close to or associated directly with the microvilli. For a conservative estimate, if we assume that between 10 and 50 particles in each section are found to have crossed the peritrophic membrane and be either associated with or close to microvilli, assuming that each section is an exact $70 \mathrm{~nm}$ thick cross section of the gut and we estimate the length of the midgut to be $500 \mu \mathrm{m}$, then it would very roughly estimated amount to between 70000 and 350000 particles per animal. The difference between our findings and the study by Lovern et al. [6] may result from different NP sizes in the experiments, as the Au NPs in our study were smaller (10 nm). Heinlaan et al. [8] monitored D. magna at 6 time points up to $48 \mathrm{~h}$ exposure to $30 \mathrm{~nm} \mathrm{CuO} \mathrm{NPs} \mathrm{and} \mathrm{only} \mathrm{at} 48 \mathrm{~h}$ found NPs close to microvilli. These differences indicate that the peritrophic membrane might act as an initial size-dependent barrier. Internalization via the gut epithelium in D. magna has been shown for ZnO NPs with the most efficient uptake of 10-30 nm particles [10]. The NPs were internalized and found inside microvilli and gut cells at various locations, as well as in the gut muscles indicating that they were able to cross the basal lamina as well. The animals in that study were also exposed for 48 hours. It is thus very likely that time and size are both 
important factors for uptake of NPs when considering that particles have to cross the peritrophic membrane first. In contrast to these time-scales, Rosenkranz et al. [33] performed a study of uptake of negatively charged fluorescent polystyrene beads $(20 \mathrm{~nm}$ and $1 \mu \mathrm{m})$ in the gut of $D$. magna where both particle sizes were shown to translocate from the gut to lipid storage bodies distant from the gut by confocal laser scanning microscopy within 30-60 minutes. This suggests that the translocation through the epithelial layer could also be relatively fast. Indeed fast translocation has recently been shown by the use of a layer of epithelial cells in vitro [34]. Together these findings suggest that future studies should include both short and long exposure times and include several particle sizes.

\section{CONCLUSIONS}

$10 \mathrm{~nm} \mathrm{Au} \mathrm{NPs} \mathrm{can} \mathrm{be} \mathrm{taken} \mathrm{in} \mathrm{and} \mathrm{accumulate} \mathrm{in} \mathrm{the} \mathrm{gut} \mathrm{lumen} \mathrm{of} \mathrm{D.} \mathrm{magna.} \mathrm{These} \mathrm{particles}$ are able to pass the PTM mainly as single particles, thus gaining access to the microvilli of the gut epithelial cells and attaching to these as observed after 24 hours of exposure. It is becoming increasingly recognized that TEM images of various nanomaterials in biological samples can be misinterpreted $[11,12,35]$. Our findings show that some form of elemental analysis is necessary for the identification of internalized NPs using TEM. As presence of Au NPs was confirmed in cells with disrupted membranes, there are two possibilities of false positive observations of NP internalization, either resulting from preparation artefacts or from mistaking holocrine cells for intact cells. By comparison to other similar studies our study also highlights the need for limiting the number of variable conditions in this type of experiments as both exposure time and NP size may influence the uptake.

Supplemental Data-The Supplemental Data are available on the Wiley Online Library at DOI: 10.1002/etc.Xxxx.

Acknowledgment - This work is part of the project ENVNANO (Environmental Effects and Risk Evaluation of Engineered Nanoparticles) supported by the European Research Council (Grant no. 
281579). Electron microscopy was performed at Center for Electron Nanoscopy, Technical University of Denmark and Core Facility for Integrated Microscopy, Copenhagen University. We acknowledge the Centre for Cellular Imaging at the Sahlgrenska Academy, University of Gothenburg for the use of light sheet microscope and for support from the staff. R. Jølck and T. Andresen are kindly thanked for synthesizing the fluorescent gold nanoparticles used for light sheet microscopy. The authors declare no competing financial interest.

Data Availability_Data available on request to the authors (louise.jensen@epfl.ch)

\footnotetext{
This article is protected by copyright. All rights reserved
} 


\section{REFERENCES}

1. Handy RD, Cornelis G, Fernandes T, Tsyusko O, Decho A, Sabo-Attwood T, Metcalfe C, Steevens JA, Klaine SJ, Koelmans AA, Horne N. 2012. Ecotoxicity Test Methods for Engineered Nanomaterials: Practical Experiences and Recommendations from the Bench. Environ Toxicol Chem 31: 15-31.

2. Hayat MA. 2000. Principles and techniques of electron microscopy: biological applications, $4^{\text {th }}$ ed, Cambridge University Press, Cambridge, UK.

3. Dudkiewicz A, Tiede K, Loeschner K, Jensen LHS, Jensen E, Wierzbicki R, Boxall ABA, Molhave K. 2011. Characterization of Nanomaterials in Food by Electron Microscopy. TrAC 30: $28-43$.

4. da Silva BF, Perez S, Gardinalli P, Singhal RK, Mozeto AA, Barcelo D. 2011. Analytical Chemistry of Metallic Nanoparticles in Natural Environments. TrAC 30: 528-540.

5. Klang V, Valenta C, Matsko NB. 2013. Electron Microscopy of Pharmaceutical Systems. Micron 44: 45-74.

6. Lovern SB, Owen HA, Klaper R. 2008. Electron Microscopy of Gold Nanoparticle Intake in the Gut of Daphnia Magna. Nanotoxicology 2: 43-48.

7. Garcia-Aonso J, Khan FR, Misra SK, Turmaine M, Smith BD, Rainbow PS, Luoma SN, Valsami-Jones E. 2011. Cellular Internalization of Silver Nanoparticles in Gut Epithelia of the Estuarine Polychaete Nereis Diversicolor. Environ Sci Technol 45: 4630-4636.

8. Heinlaan M, Kahru A, Kasemets K, Arbeille B, Prensier G, Dubourguier H-C. 2011. Changes in the Daphnia Magna Midgut upon Ingestion of Copper Oxide Nanoparticles: A Transmission Electron Microscopy Study. Water Res 45: 179-190.

This article is protected by copyright. All rights reserved 
9. Khan FR, Kennaway GM, Croteau MN, Dybowska A, Smith BD, Nogueira AJA, Rainbow PS, Luoma SN, Valsami-Jones E. 2014. In Vivo Retention of Ingested Au NPs by Daphnia Magna: No Evidence for Trans-Epithelial Alimentary Uptake. Chemosphere 100: 97-104.

10. Santo N, Fascio U, Torres F, Guazzoni N, Tremolada P, Bettinetti R, Mantecca P, Bacchetta R. 2014. Toxic Effects and Ultrastructural Damages to Daphnia Magna of Two Differently Sized ZnO Nanoparticles: Does Size Matter? Water Res 53: 339-350.

11. Edgington AJ, Petersen EJ, Herzing AA, Podila R, Rao A, Klaine SJ. 2014. Microscopic Investigation of Single-Wall Carbon Nanotube Uptake by Daphnia Magna. Nanotoxicology 8: 2-10.

12. Brandenberger C, Clift MJD, Vanhecke D, Muhlfeld C, Stone V, Gehr P, Rothen-Rutishauser B. 2010. Intracellular Imaging of Nanoparticles: Is it an Elemental Mistake to Believe What You See? Part Fibre Toxicol 7: 15.

13. Bednarska A. Adaptive Changes in Morphology of Daphnia Filter Appendages in Response to Food Stress. 2006. Pol J Ecol 54: 663-667.

14. Gerritsen J, Porter KG, Strickler JR. 1988. Not by Sieving Alone - Observations of Suspension Feeding in Daphnia. Bull Mar Sci 43: 366-376.

15. Bianchini A, Wood CM. 2008. Sodium Uptake in Different Life Stages of Crustaceans: The Water Flea Daphnia Magna Strauss. J Exp Biol 211: 539-547.

16. Gillis PL, Chow-Fraser P, Ranville JF, Ross PE, Wood CM. 2005. Daphnia Need to Be Gutcleared Too: The effect of Exposure to and Ingestion of Metal-Contaminated Sediment on the Gut-clearance Patterns of D-Magna. Aquat Toxicol 71: 143-154.

17. Skjolding LM, Kern K, Hjorth R, Hartmann N, Overgaard S, Ma G, Veinot JGC, Baun A. 2014. Uptake and Depuration of Gold Nanoparticles in Daphnia Magna. Ecotoxicology 23: 11721183.

This article is protected by copyright. All rights reserved 
18. Lee BT, Ranville JF. 2012. The Effect of Hardness on the Stability of Citrate-Stabilized Gold Nanoparticles and Their Uptake by Daphnia Magna. J Hazard Mater 213: 434-439.

19. Yang XY, Edelmann RE, Oris JT. 2010. Suspended C-60 Nanoparticles Protect Against ShortTerm UV and Fluoranthene Photo-Induced Toxicity but Cause Long-Term Cellular Damage in Daphnia Magna. Aquat Toxicol 100: 202-210.

20. Zhu XS, Chang Y, Chen YS. 2010. Toxicity and Bioaccumulation of TiO2 Nanoparticle Aggregates in Daphnia Magna. Chemosphere 78: 209-215.

21. Lee WM, Yoon SJ, Shin YJ, An YJ. 2015. Trophic Transfer of Gold Nanoparticles from Euglena Gracilis or Chlamydomonas Reinhardtii to Daphnia Magna. Environ Pollut 201: 10-16. 22. Jølck RI, Rydhög JS, Christensen AN, Hansen AE, Bruun LM, Schaarup-Jensen H, von Wenck AS, Børresen B, Kristensen AT, Clausen MH, Kjær A, Conradsen K, Larsen R, af Rosenschöld PM, Andresen TL. 2015. Injectable Colloidal Gold for Use in Intrafractional 2D Image-Guided Radiation Therapy. Adv Healthcare Mater 4: 856-863.

23. OECD (Organisation for Economic Co-operation and Deevelopment) 2004. F. Test no. 202: Daphnia Sp. Acute Immobilisation Test OECD France.

24. Hardy WB, McDougall W. 1893. On the Structure and Functions of the Alimentary Canal of Daphnia. Proc Camb Phil Soc VIII: 41.

25. Rothen-Rutishauser B, Kuhn DA, Ali Z, Gasser M, Amin F, Parak WJ, Vanhecke D, Fink A, Gehr P, Brandenberger C. 2014. Quantification of Gold Nanoparticle Cell Uptake under Controlled Biological Conditions and Adequate Resolution. Nanomedicine 9: 607-621.

26. Lehane MJ. 1997. Peritrophic Matrix Structure and Function. Annu Rev Entomol 42: 525-550.

27. Schultz TW, Kennedy JR. 1976. The Fine Structure of the Digestive System of Daphnia Pulex (Crustacea: Cladocera). Tissue Cell 8: 479-490.

This article is protected by copyright. All rights reserved 
28. Wang TT, Bai J, Jiang X, Nienhaus GU. 2012. Cellular Uptake of Nanoparticles by Membrane Penetration: A Study Combining Confocal Microscopy with FTIR Spectroelectrochemistry. ACS Nano 6: 1251-1259.

29. Rothen-Rutishauser BM, Schuerch S, Haenni B, Kapp N, Gehr P. 2006. Interaction of Fine Particles and Nanoparticles with Red Blood Cells Visualized with Advanced Microscopic Techniques. Environ Sci Technol 14: 4353-4359.

30. Cartiera MS, Johnson KM, Rajendran V, Caplan MJ, Saltzman WM. 2009. The Uptake and Intracellular Fate of PLGA Nanoparticles in Epithelial Cells. Biomaterials 30: 2790-2798.

31. Cho EC, Xie J, Wurm PA, Xia Y. 2009. Understanding the Role of Surface Charges in Cellular Adsorption versus Internalization by Selectively Removing Gold Nanoparticles on the Cell Surface with a I-2/KI Etchant. Nano Lett 9: 1080-1084.

32. Treuel L, Jiang XE, Nienhaus GU. 2013. New Views on Cellular Uptake and Trafficking of Manufactured Nanoparticles. J R Soc Interface 10: 20120939.

33. Rosenkranz P, Chaudhry Q, Stone V, Fernandes TF. 2009. A Comparison of Nanoparticle and Fine Particle Uptake by Daphnia Magna. Environ Toxicol Chem 28: 2142-2149.

34. Yao MF, He LL, McClements DJ, Xiao H. 2015. Uptake of Gold Nanoparticles by Intestinal Epithelial Cells: Impact of Particle Size on Their Absorption Accumulation and Toxicity. J Agric Food Chem 63: 8044-8049.

35. Kobler C, Saber AT, Jacobsen NR, Wallin H, Vogel U, Qvortrup K, Molhave K. 2014. FIBSEM Imaging of Carbon Nanotubes in Mouse Lung Tissue. Anal Bioanal Chem 406: 38633873.

This article is protected by copyright. All rights reserved 
Figure 1. Cryo-TEM image of Au NP stock solution. The particles are non-aggregated, scale bar $=300$ $\mathrm{nm}, *$ = lacey carbon support.

Figure 2. D. magna after (A) 0 h, (B) 2 h, (C) 4 h and (D) 24h exposure to Au NPs (0.4 mg Au/L) using a 5x magnification water immersed objective. The red and white color in the image corresponds to FITC tag $(505-545 \mathrm{~nm})$ and auto fluorescence of the daphnia $(575-615 \mathrm{~nm})$ respectively. Scale bars 0.5 $\mathrm{mm}$.

Figure 3. FIB-SEM BSE images of D. magna gut epithelium after $24 \mathrm{~h}$ exposure to Au NPs (0.4 mg $\mathrm{Au} / \mathrm{L})$. Electron dense structures appear white. Examples of Au NP-like objects are marked with arrows. (A) Scale bar $=1 \mu \mathrm{m}$, (B) scale bar $=0.5 \mu \mathrm{m}$. GC = gut cells, $\mathrm{LU}=$ Lumen, $\mathrm{MV}=\mathrm{Microvilli}$, $\mathrm{PTM}=$ Peritrophic membrane.

Figure 4. D. magna gut epithelium after 24h exposure to Au NPs (0.4 mg Au/L). Overview of gut lumen and microvilli, scale bar $=0.5 \mu \mathrm{m} .{ }^{*}=\mathrm{Au}$ NP- like objects. GC $=$ gut cells, $\mathrm{MV}=\mathrm{Microvilli}$, PTM = Peritrophic membrane. Arrows point to electron dense particles and aggregates .

Figure 5. TEM images of D. magna gut epithelium exposed to Au NPs (0.4 mg Au/L) for 24h. (A) Electron dense particles attached to microvilli (arrows). Scale bar $=200 \mathrm{~nm}$ and (B) intracellular structures and objects which resemble NPs (inserts). Scale bar $=200 \mathrm{~nm}$ and inserts $=5 \mathrm{~nm}$.

Figure 6. HAADF STEM images of D. magna gut epithelium exposed to Au NPs (0.4 mg Au/L) for 24h showing intracellular structures and possible NPs. Corresponding spectra are superimposed. For clarity the C-peaks are capped and only up to $2.5 \mathrm{keV}$ is depicted. (A) Au NP at microvilli, scale bar = $100 \mathrm{~nm},(\mathrm{~B}) \mathrm{Au} \mathrm{NP}$ at base of microvilli, scale bar $=100 \mathrm{~nm},(\mathrm{C})$ Os-rich particles in mitochondrion, scale bar $=300 \mathrm{~nm}$, (D) Os-rich particles in lipid droplet, scale bar = $50 \mathrm{~nm}$, (E) Aggregate of Fe-rich particles below the basal lamina, scale bar $=0.5 \mu \mathrm{m},(\mathrm{F}) \mathrm{Au}$ NP in a holocrine cell, scale bar $=200$ nm.

This article is protected by copyright. All rights reserved 


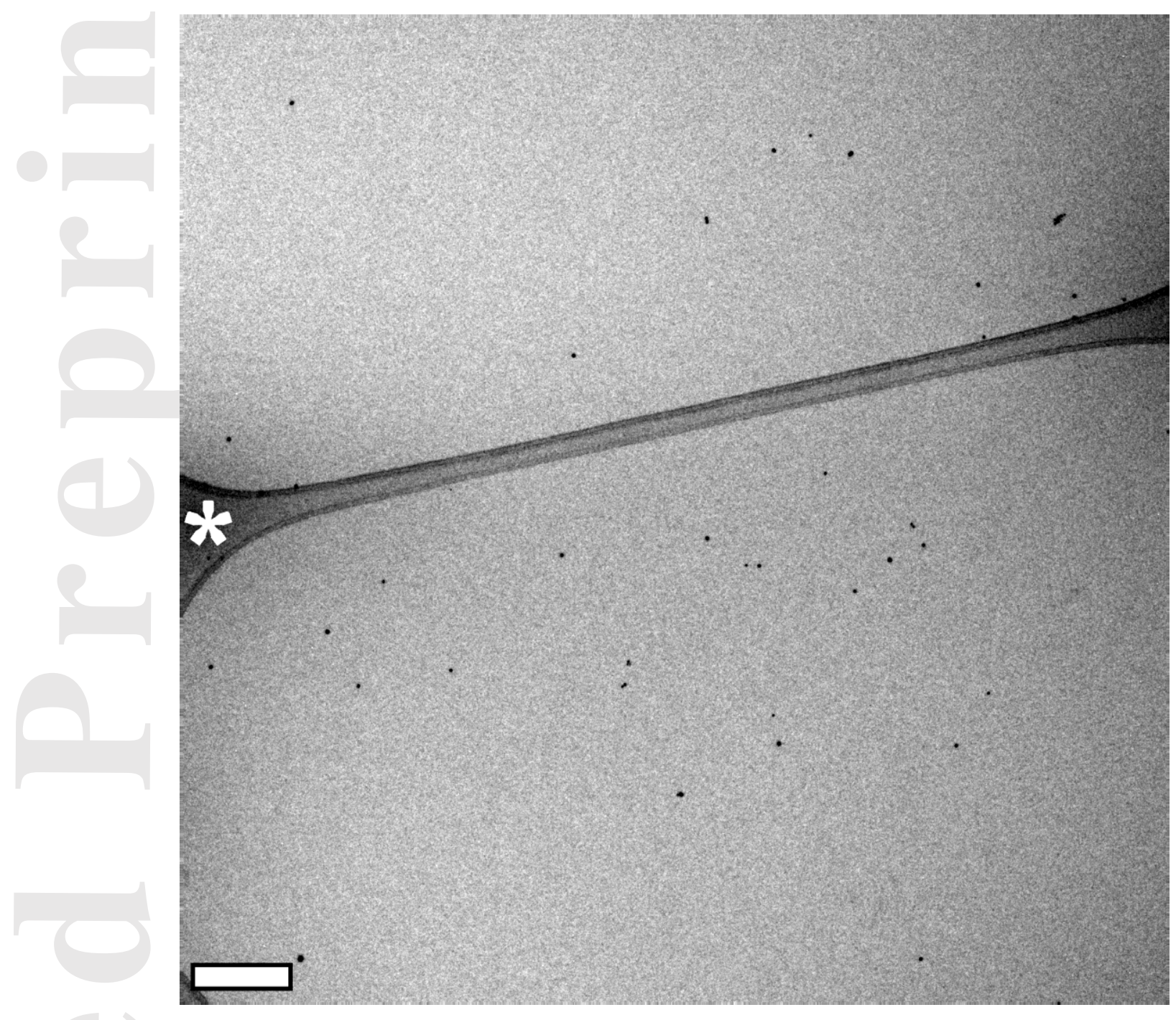

Figure 1

This article is protected by copyright. All rights reserved 


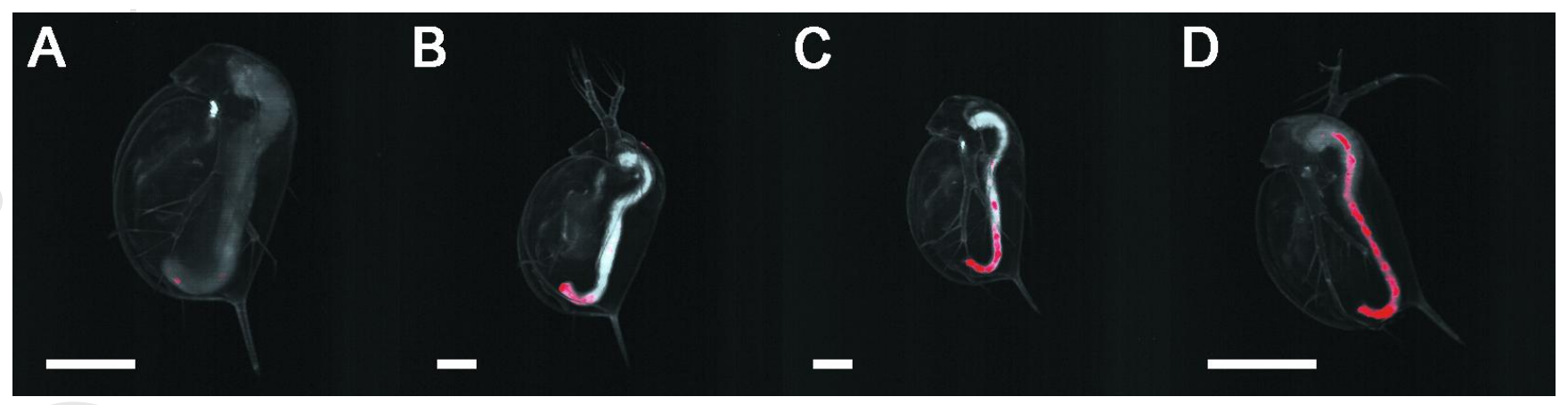

Figure 2

This article is protected by copyright. All rights reserved 


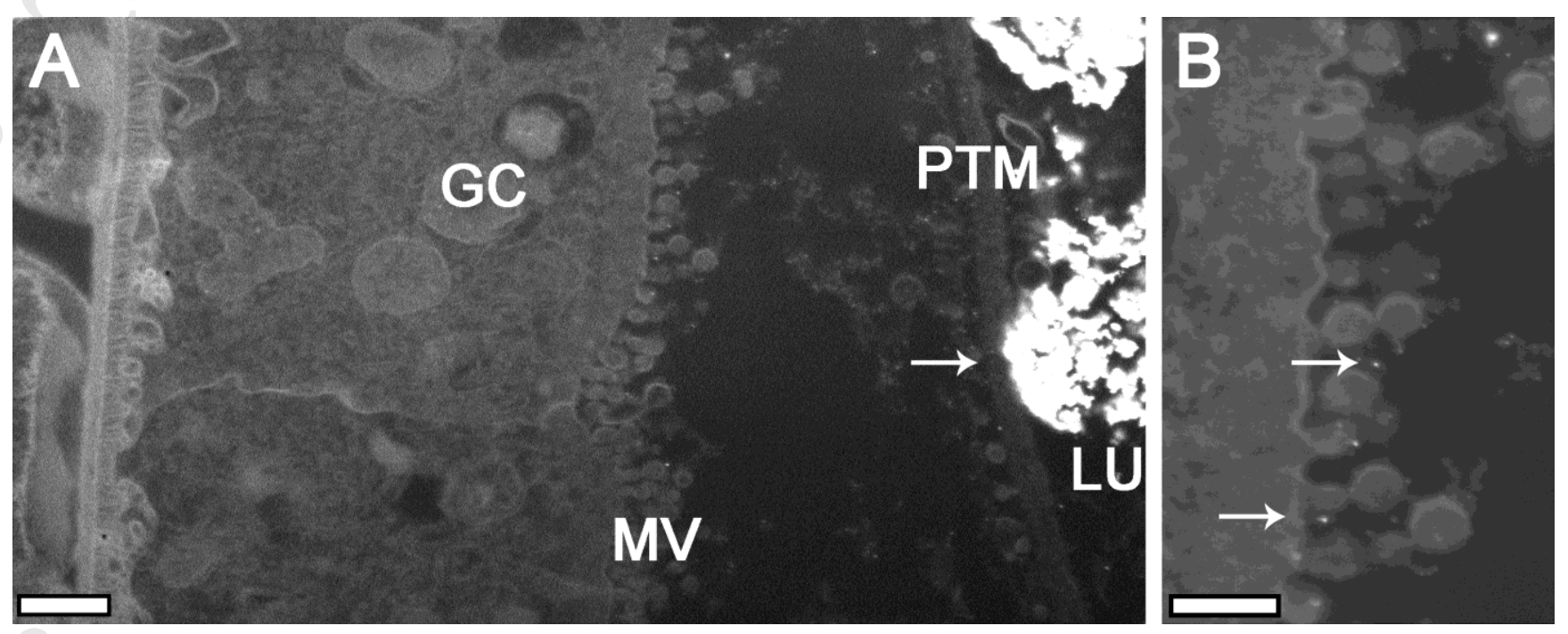

Figure 3
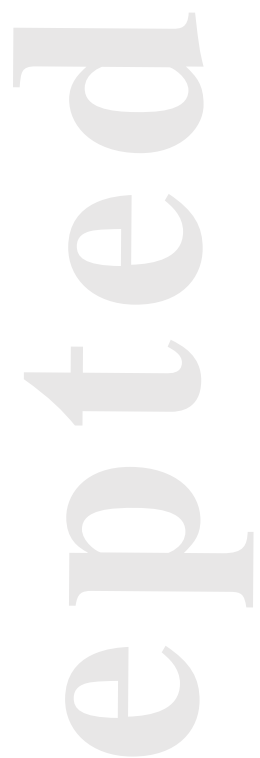

This article is protected by copyright. All rights reserved 


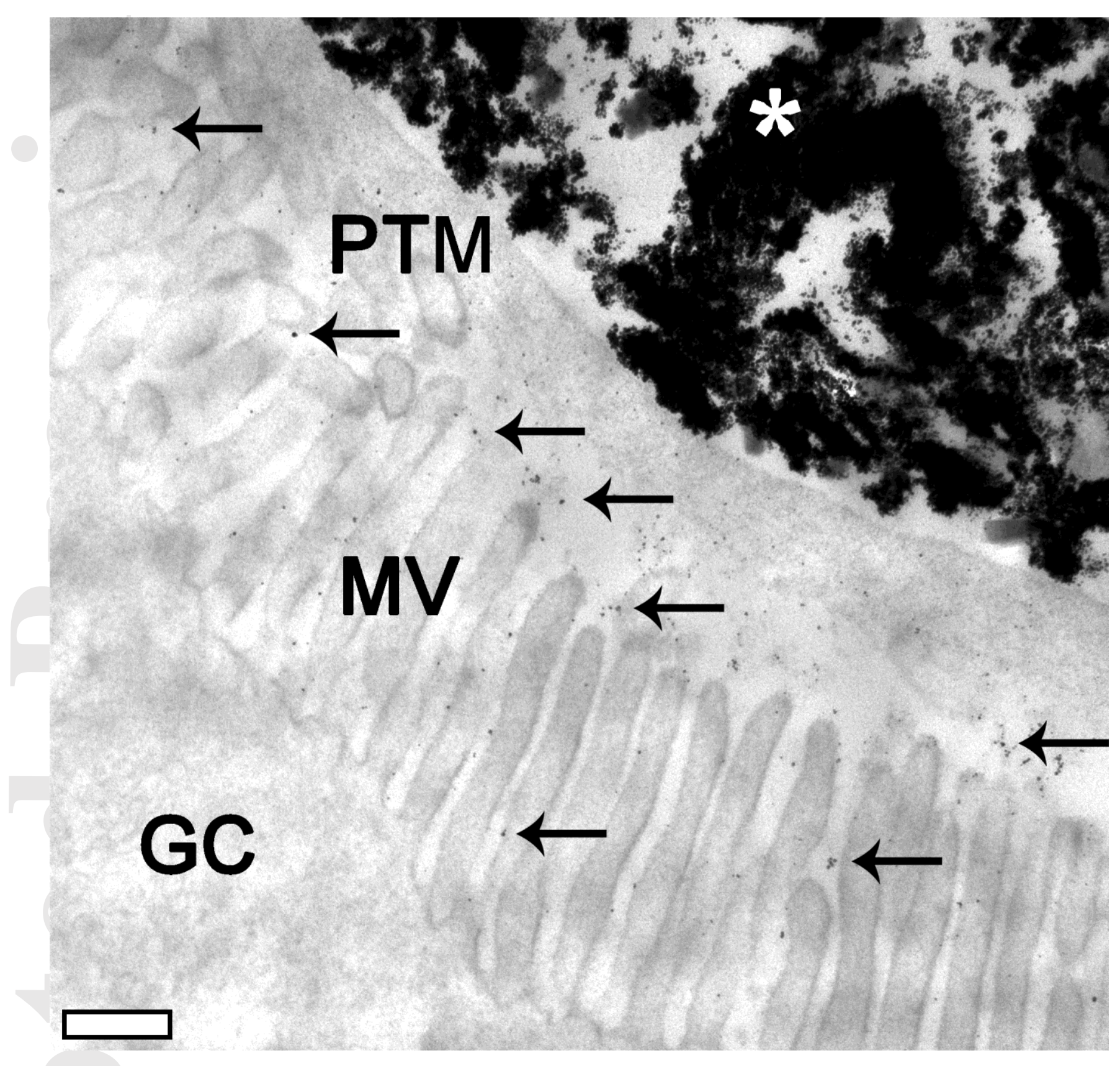

Figure 4

This article is protected by copyright. All rights reserved 

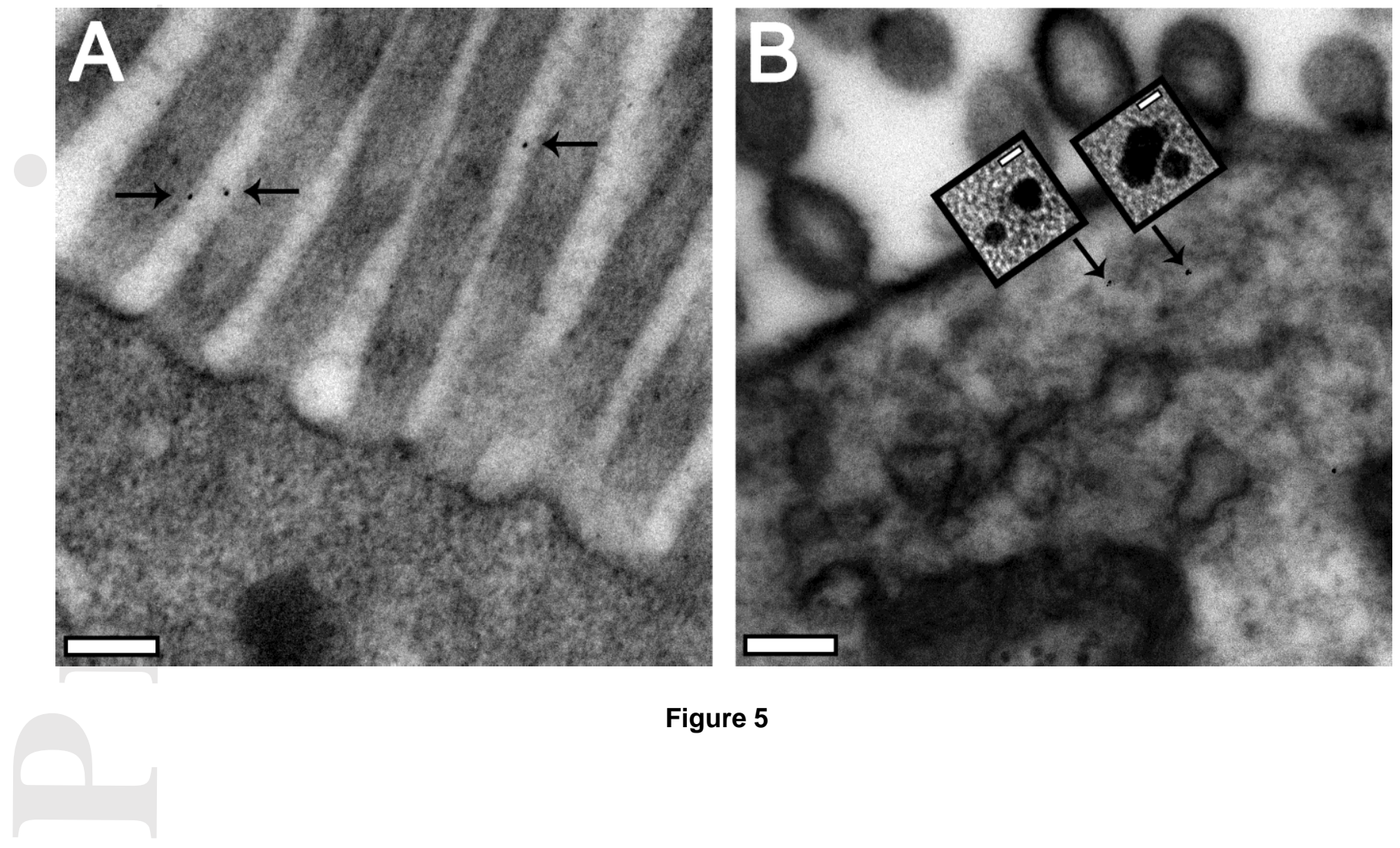

Figure 5
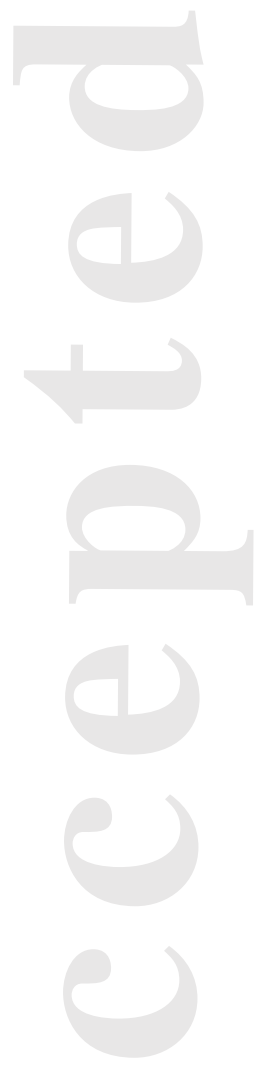

This article is protected by copyright. All rights reserved 


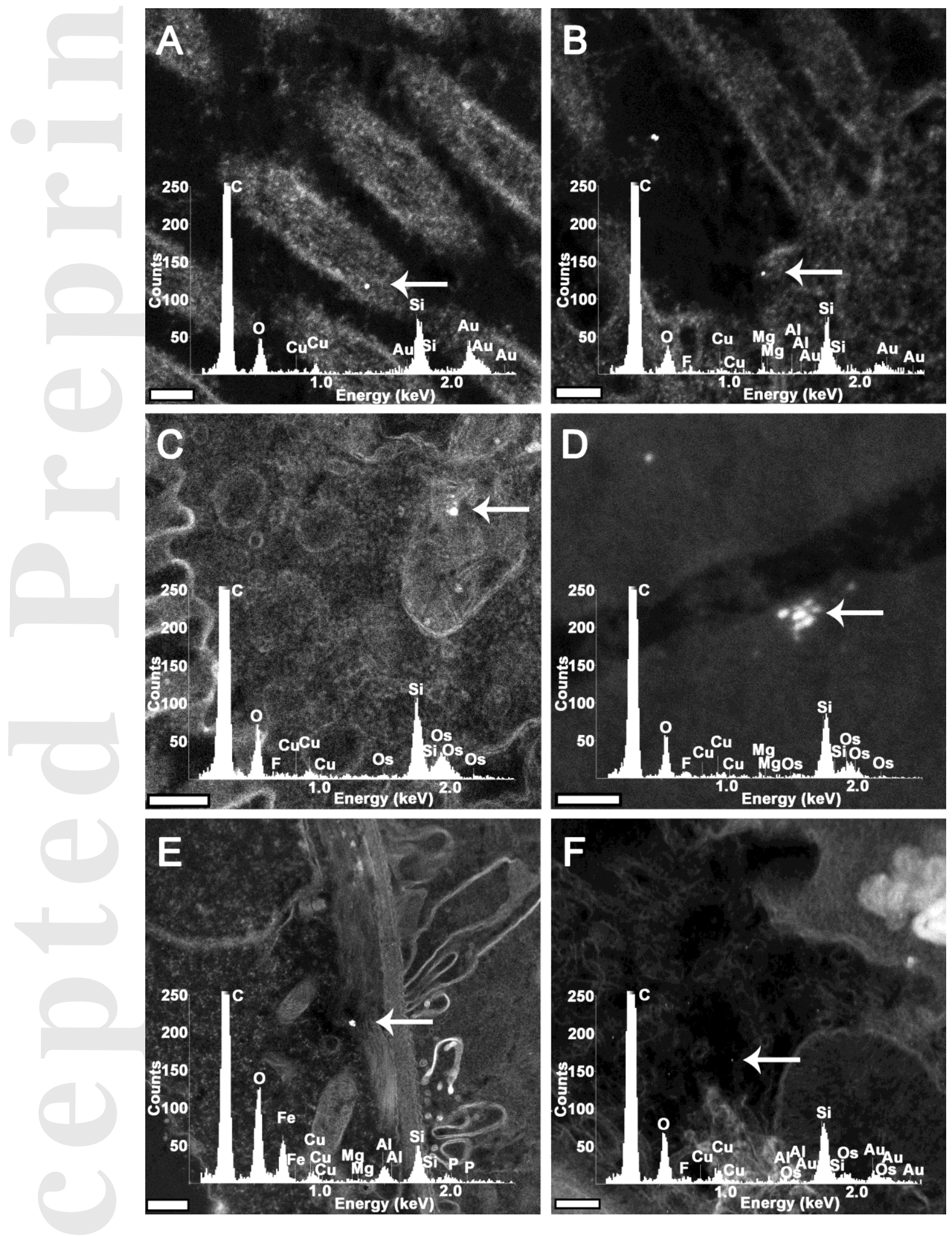

Figure 6

This article is protected by copyright. All rights reserved 